\title{
SPONTANEOUS CURE OF EMPYEMA OF THE ANTRUM.
}

\author{
By W. LAMB, M.D., Birmingham.
}

\section{(Plates Vl. AND VIL.)}

THE specimen depicted in the accompanying Plates came into my possession while I was working at the anatomy of the accessory sinuses of the nose. As the condition represented is one of considerable rurity and interest, $I$ venture to think it worthy of record.

Plate VI. represents the outer wall of the nose, with the middle turbinal partly detached and turned up. The first thing that strikes one is the presence of a depressed and pitted cicatrix in the middle meatus. This cicatrix occupies practically the whole of the middle meatus, but it is most marked at the anterior part, especially over an area somewhat triangular in shape, with the apex of the triangle at the anterior attachment of the midlle spongy bone. This is the position in which pus from the antrum is generally seen. Plate VII. shows the other side of the specimen. The cheek has been divided and turned up, and the facial wall of the antrum has been removed so as to expose the cavity.

Projecting upwards from the floor of the antrum is a cylindrical tube of bone about $3 \mathrm{~mm}$. in length. The open lumen of the tube is seen in the ilustration, but when the antrum was opened the tube was perfectly covered with continuous mucous membrane, and looked like a peg sticking up into the cavity. On scraping off the mucous membrane, the lumen of the tube was exposed, crossed here and there by little spicules of bone. On tracing it down, it was found to open into the top of the socket of the palatal fang of the second molar tooth. The tooth is quite firm in its socket, but there is a large carious cavity in the posterior part of the crown, and the pulp cavity of the palatal fang is freely exposed. The walls of this carious cavity are black, and show no signs of having been prepared by a dentist, but a filling of platinum amalgam has been tightly packed in on the top of a pledget of wadding soaked in some yellowish liquid, probably creasote.

The sequence of events was probably as follows:-First, there

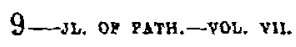


was dental caries, which spread to the floor of the antrum, causing purulent infection of the cavity, and leading to the establishment of a chronic empyema.

The empyema persisted for a long time, and the pus overflowed through the ostium maxillare into the middle meatus in the usual way, giving rise to a local atrophic rhinitis, of which we see the evidences in the depressed and pitted cicatrix. In course of time a carious opening formed in the floor of the antrum, and the pus began to drain downwards into the palatal socket of the second molar, whence it escaped into the mouth, probably through the fang, perhaps also through the socket by the side of the fang. New bone was deposited round this drainage opening, in the same way that it is deposited round the hole made by a drill, and the little bony tube was thus gradually built up. Finally, suppuration ceased; the mucous membrane covered the end of the tube, and the patient had the carious tooth filled in the somewhat primitive fashion I have described.

Spontaneous cure of empyema of the antrum is probably very rare. Siebenmann recorded a case in which drainage took place through the open socket of a tooth. In this case, however, the tooth remained firmly fixed in its socket. 


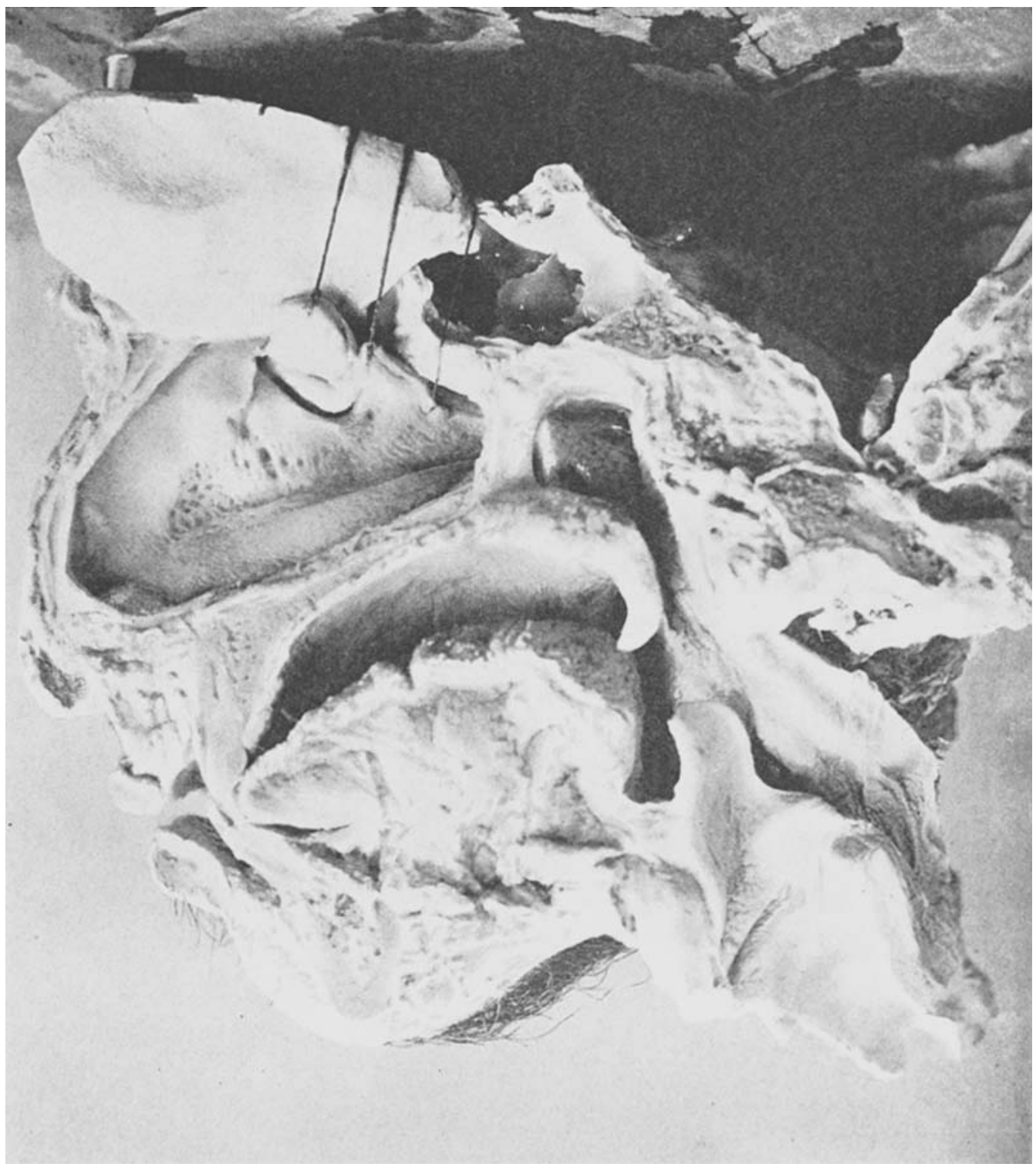




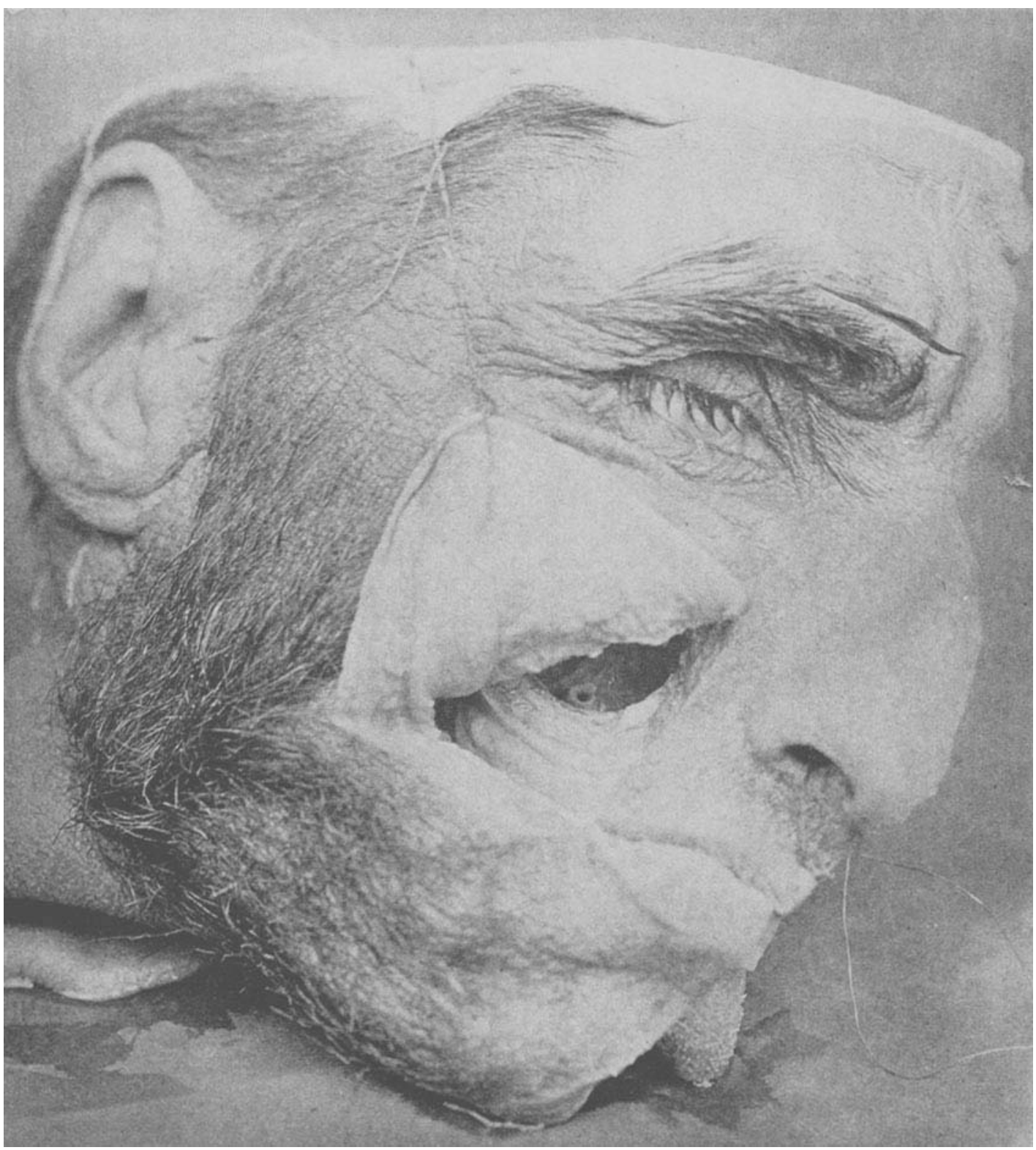

